\title{
Control of heat exchangers in series using neural network predictive controllers
}

\author{
Anna Vasičkaninová, Monika Bakošová, Alajos Mészáros \\ Slovak University of Technology in Bratislava, Faculty of Chemical and Food Technology, \\ Institute of Information Engineering, Automation and Mathematics, \\ Radlinského 9, 81237 Bratislava, Slovak Republic \\ anna.vasickaninova@stuba.sk
}

\begin{abstract}
The paper reveals three applications of neural network predictive control (NNPC) to a system of four heat exchangers (HEs) in series with counterflow configuration to save energy expressed by cooling water in the system of HEs cooling the distillation product. Neural networks (NNs) are used at first in conventional NNPC and subsequently, neural network predictive controllers (NNPCLs) are employed as a master controller in a cascade control, and as a feedback controller in the control system with disturbance measurement. Neuralnetwork-predictive-control-based (NNPC-based) feedback control systems are compared with PI controller based feedback control loop. Series of simulation experiments were done and the results showed that using NNPC-based cascade control reduced cooling water consumption. This control system also significantly reduced the settling time and overshoots in the control responses and provided the best assessed integral quality criteria compared to other control systems. NNPG-based cascade control can also be interesting for industrial use. Generally, simulation results proved that NNPC-based control systems are promising means for the improvement of HEs control and achievement of energy saving.
\end{abstract}

Keywords: heat exchanger; neural network predictive control; neural-network-predictive-control-based cascade control; neural-network-predictive-control-based control system with disturbance measurement

\section{Introduction}

In contemporary industrial and technological world characterized by increasing energy demands and energy prices, energy consumption and clean energy utilization belong to the most important global challenges. Sustainability requirements on all production processes and especially on energy intensive processes are also intensified to save our planet for future generations. Industrial production cannot do without HEs, which are used to exchange heat between media. Efficient heat recovery in an industrial plant is also a challenging task and one possibility is to combine HEs optimally in heat exchanger networks (HENs). Pashchenko (2020) published the calculation method for recovery rate as the main measure of heat recovery efficiency in a thermochemical waste-heat recuperation plant. Advanced control systems represent the other technical solution for efficient heat recovery. Markowski and Trzcinski (2019) introduced the HEN mathematical model and on-line control algorithm to maximize heat recovery.

From the viewpoint of heat, cold, vapor or electricity production continuous improvement, HEs and HENs have become the midpoint of research and development. Saranya et al. (2017) modeled various types of heat exchangers, i.e., plate type HE, spiral type HE and shell and tube type HE. They also compared different model-based and non-model-based control systems and stated that NNs can act as controllers. Nemet et al. (2017) designed HEN with improved safety during its whole lifetime. Secure HEN was obtained considering the risk in the early phase of the synthesis by including the changing failure frequency. Sun et al. (2018) investigated two different enhanced ejector heat exchangers and presented a configuration that optimizes exergy efficiency. Baruque et al. (2019) designed a heat exchanger as a part of a geothermal system and helped to regulate temperature by means of the developed prediction system. Thermally integrated preheater and heat exchanger network configurations were used by Yang et al. (2019) to save energy. The proposed method can be extended to other industrial processes that diminish energy spending and $\mathrm{CO}_{2}$ emissions. Elsisi (2019) proposed a new predictive control system for energy conversion in a wind system. Controller parameters were tuned by a new intelligence technique called the crow search algorithm. Controller efficiency was confirmed in various situations with changes in the load requirements, wind speed, and the presence of system parameter uncertainties. Kim et al. (2009) presented an effective strategy to minimize the total annual cost of designing $\mathrm{HE}$ and wastewater networks. Cost estimates for optimized HE and wastewater networks in the oil refining process were assessed to illustrate the efficiency of the proposed strategy. Yang et al. (2016) introduced a systematic 
and comprehensive comparative methodology that can be used to assess energy efficiency and energy saving potential of an energy-intensive chemical production system. The proposed approach was implemented to reduce energy consumption and to identify the most advanced energy use system.

Intensive research has been done in advanced control of various types and configurations of heat exchangers. Vasičkaninová and Bakošová (2015) successfully applied neural network and fuzzy system in a control system with the NNPC-based main and a fuzzy auxiliary controller to control a tubular HE. NNPC of tubular HEs in series with counter current configuration was introduced by Vasičkaninová et al. (2017), ensuring energy savings compared to PID control. Bakošová et al. (2017) compared NNPG, robust model-based predictive control (RMPC) and PID control in tubular HEs control, examined in set-point tracking. Simulation results proved better closed-loop control performance and energy savings measured by hot water consumption for NNPG and RMPG over conventional PID control. Oravec et al. (2018) designed RMPC with integral action and implemented this control strategy for shell-and-tube HEs with fouling and proving considerable improvement in control performance and energy savings in contrast to conventional PID control.

This paper exceeds the paper by Vasičkaninová et al. (2019). The aim of the research represented by results in this paper is to show that NNPCbased control systems are very attractive for HEs operation improvement as they provide higher energy efficiency, lower carbon footprint and cooling water savings. Especially water savings are very important for sustainable management of natural freshwater resources, for the protection of the aquatic environment and for meeting the current and future human needs.

\section{Controlled process description}

Optimal operation of HEs and HENs is one of the tools of energy saving in the process industry ensuring the integration of heat between hot and cold process streams to reduce heat and cold consumption during the heat exchange process.

Based on the previous work (Vasičkaninová et al., 2017), four identical shell-and-tube HEs in series with counter current flow configuration create the controlled process (Fig. 1). Two main objectives of control are to decrease the temperature of kerosene in the outlet stream from the $4^{\text {th }} \mathrm{HE}$ to the reference temperature and to minimize the cooling water consumption.

A simplified nonlinear dynamic mathematical model of the HEs can take the form of eight firstorder differential equations (Oravec et al., 2016). Values of the parameters and steady-state inputs of HEs are given in Vasičkaninová et al. (2017).

Water is used as a coolant and flows in the shell of each HE, kerosene flows in the inner tubes. Tubes as well as shell are constructed of steel.

The first-principle nonlinear dynamic mathematical model of HEs (Fig. 1) reflecting the energy balances and heat transfer relations was derived in a simplified form and it contains eight first-order ordinary differential equations (Oravec et al., 2016). Four differential equations (1) describe the dynamics of cold fluid and the other four differential equations (2) represent the dynamics of hot fluid.

$$
\begin{gathered}
\frac{\mathrm{d} T_{1}^{j}(t)}{\mathrm{d} t}= \\
=k_{1}\left(\left(T_{2}^{j}(t)-T_{1}^{j+1}(t)\right)+\left(T_{2}^{j-1}(t)-T_{1}^{j}(t)\right)\right)+ \\
+k_{2}\left(T_{2}^{j}(t)-T_{1}^{j+1}(t)\right), T_{1}^{j}(0)=T_{1,0}^{j} \\
\frac{\mathrm{d} T_{2}^{j}(t)}{\mathrm{d} t}= \\
=k_{3}\left(\left(T_{2}^{j}(t)-T_{1}^{j+1}(t)\right)+\left(T_{2}^{j-1}(t)-T_{1}^{j}(t)\right)\right)+ \\
+k_{4}\left(T_{2}^{j}(t)-T_{1}^{j+1}(t)\right), T_{2}^{j}(0)=T_{2,0}^{j}
\end{gathered}
$$

where

$$
k_{1}=\frac{A U}{2 V_{1} \rho_{1} c_{p 1}}, k_{2}=\frac{q_{1}}{V_{1}}, k_{3}=\frac{A U}{2 V_{2} \rho_{2} c_{p 2}}, k_{4}=\frac{q_{2}}{V_{2}}
$$

In (1)-(3), subscripts 1 and 2 indicate the heated and the heating stream, respectively. Superscript $j=1, \ldots, 4$ denotes the heat exchanger. Temperatures $T_{1}^{j}(0)=T_{1,0}^{j}, T_{2}^{j}(0)=T_{2,0}^{j}$ are the initial conditions, i.e. temperatures in a steady-state operation regime of the HEs and they can be calculated using the steady-state model of HEs represented by (1)-(3) with zero derivatives at the left-hand sides. Further, $t$ is time, $T$ is temperature, $A$ is the heat transfer area, $U$ is the overall heat transfer coefficient, $V$ is

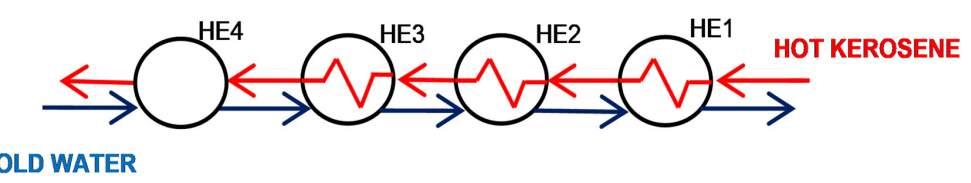

Fig. 1. Shell-and-tube heat exchangers in series with counter current flow configuration. 
the volume of fluid in the HE, $\rho$ is the density, $c_{p}$ is the specific heat capacity and $q$ is the volumetric flow rate of the fluid (Vasičkaninová et al., 2017).

\section{Basic concepts of NNPC}

The scheme in Fig. 2 illustrates the predictive control based on the NN model. The neural network predictive controller contains an NN model and an optimization block. The controller predicts process output variables based on the values of $\mathrm{NN}$ model output variables while the optimization block calculates control inputs.

The controlled process can be nonlinear and affected by various uncertainties. In NNPC, it is important to obtain a process model based on $\mathrm{NN}$ which is trained based on a prediction error representing the difference between the measured process output and the predicted neural network output (Soloway and Haley, 1996).

The quadratic performance function (4) is minimized to provide the optimum sequence of control inputs and only the first control input of the sequence is applied on the controlled nonlinear plant.

$$
\begin{aligned}
E(k)= & \sum_{j=N_{1}}^{N_{2}}\left(r(k+j)-y_{m}(k+j)\right)^{2}+ \\
& +\lambda \sum_{j=1}^{N_{u}}(\Delta u(k+j-1))^{2}
\end{aligned}
$$

Performance function parameters are: $N_{1}-$ minimum prediction horizon, $N_{2}$ - maximum prediction horizon and $N_{u}-$ control horizon. Prediction horizons $N_{1}, N_{2}$ indicate the future time interval in which it is desirable to track the reference trajectory $r, k$ denotes discrete time, $i$ is the order of the predictor, positive number $\lambda$ represents weight factor expressing the contribution of the control increments to the cost function, $y_{m}$ is the NN model output, and $\Delta u$ is the sequence of future control increments (Beale et al., 2015).
The above described NN predictive control structure uses a two-layer NN process model with sigmoid hidden-layer transfer functions and linear output-layer transfer functions. The network is usually trained off-line in batch mode using data gathered by measuring of the controlled process outputs. The Levenberg-Marquardt (LM) training algorithm for the $\mathrm{NN}$ model is commonly used (Lera and Pinzolas, 2002). Due to the convergence properties, the LM algorithm has become a widely adopted standard technique for nonlinear leastsquares problems. It iteratively searches a minimum of the sum of nonlinear function squares according to Eq. (5):

$$
x(k)=x(k+1)+\left(J^{T} J+\mu I\right)^{-1} J^{T} e(k)
$$

where $I$ is the identity matrix, $J$ denotes the Jacobian matrix from the difference of error to the weight value, $e$ denotes the control error and $\mu$ is a damping parameter representing an adaptive balance between two steps. Both the success and the efficiency of the LM algorithm depend on the choice of parameter $\mu$.

\section{Conventional control of heat exchangers in series with counter current flow arrangement}

\section{Conventional PI control}

Four heat exchangers in series with counter current flow configuration described in the previous section represent the controlled process. Kerosene temperature in the outlet stream from the $4^{\text {th }}$ heat exchanger is the controlled output, and volumetric flow rate of cold water in the inlet stream into the $4^{\text {th }}$ heat exchanger is the manipulated variable. The feedback control system is presented in Fig. 3, where TG is the temperature PI controller. HEN has nonlinear and asymmetric dynamics and it is influenced by load disturbances. These distur-

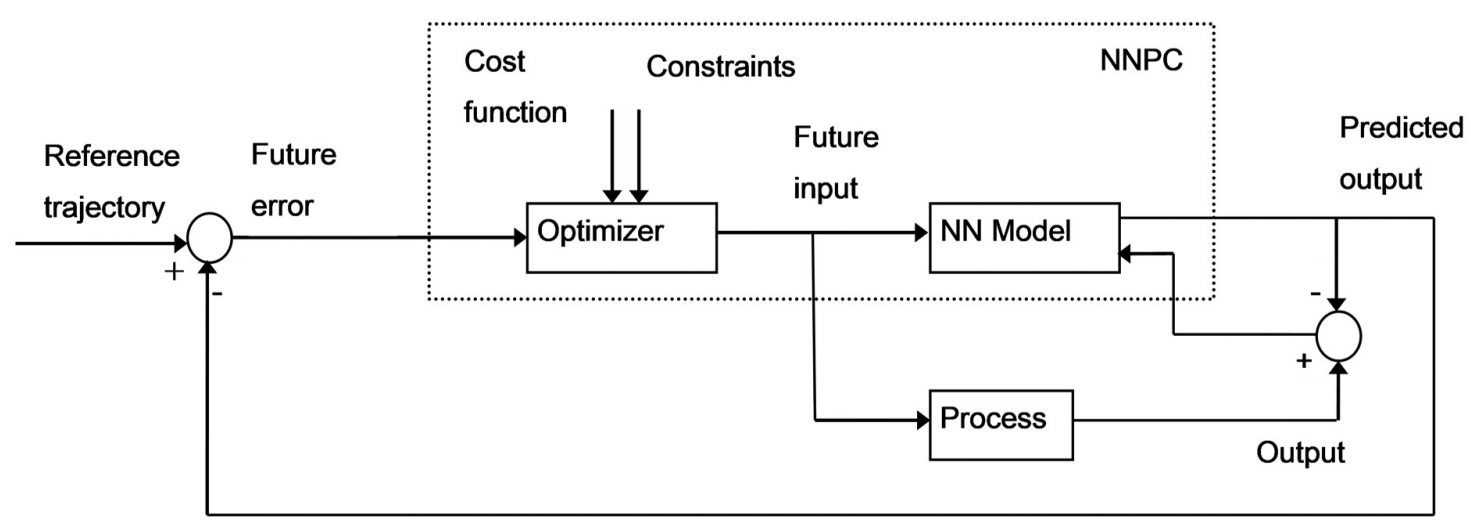

Fig. 2. Feedback control system with a neural-network-based predictive controller. 


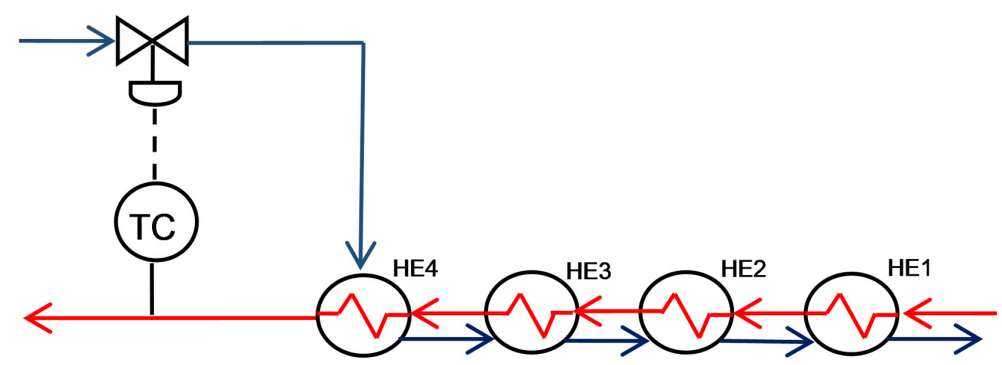

Fig. 3. Feedback control system with temperature PI controller.

bances were represented by the coolant temperature changes in the inlet stream into the first HE in the simulation experiments and they were as follows: temperature decreased by $3{ }^{\circ} \mathrm{C}$ at $t=30 \mathrm{~min}$, then increased by $4^{\circ} \mathrm{C}$ at $t=90 \mathrm{~min}$ and finally decreased by $2{ }^{\circ} \mathrm{C}$ at $t=150 \mathrm{~min}$.

The conventional PI controller is represented by the transfer function (6)

$$
C(s)=k_{p}\left(1+\frac{1}{t_{i} s}\right)=k_{p}+\frac{k_{i}}{s}=-0.1274-\frac{0.0337}{s}
$$

The controller parameters are: $k_{p}-$ proportional gain, $t_{i}$ - integral time.

For PI controller tuning, HEN was identified using the step-response-based method. The resulting model took the form of the $n$-th order plus time delay transfer function (7) with the transfer function parameters: order $n=2$, gain
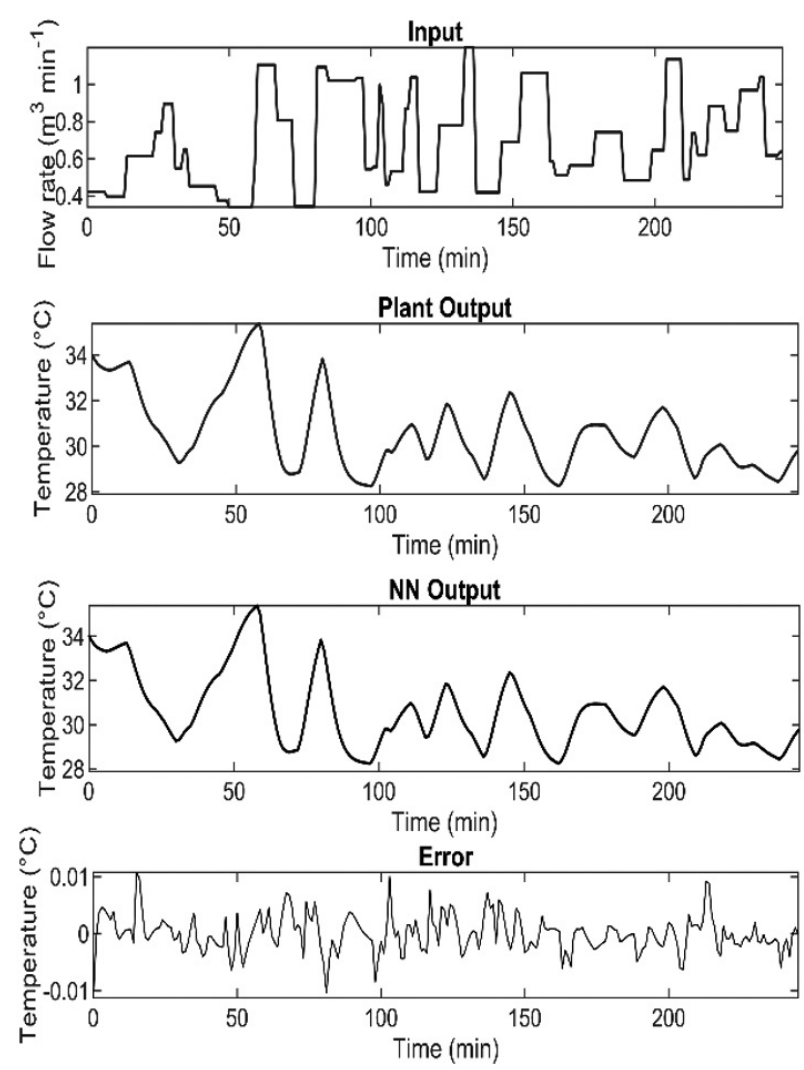

Fig. 4. Training data for NN model.
$K=-69.25{ }^{\circ} \mathrm{C} \operatorname{min~} \mathrm{m}^{-3}$, time constant $\tau=3.15 \mathrm{~min}$ and time delay $D=0.125$ min (Mikleš and Fikar, 2007). The Chien-Hrones-Reswick method was used for controller tuning (Corriou, 2004). The PI controller parameters are: $k_{p}=-0.1274^{\circ} \mathrm{C}^{-1} \mathrm{~min}^{-1} \mathrm{~m}^{3}$, $k_{i}=-0.0337{ }^{\circ} \mathrm{C}^{-1} \mathrm{~min}^{-2} \mathrm{~m}^{3}$. Negative values of controller parameters reflect the fact that an increase of cooling fluid flow rate decreases the temperature of hot fluid.

$$
P(s)=\frac{K}{(\tau s+1)^{n}} e^{-D s}=\frac{-69.25}{(3.15 s+1)^{2}} e^{-0.125 s}
$$

\section{Conventional neural network predictive control of $\boldsymbol{H E s}$}

As mentioned above, the NN process model has first to be trained (Vasičkaninová et al., 2017) to design NNPC. The neural network had four delayed
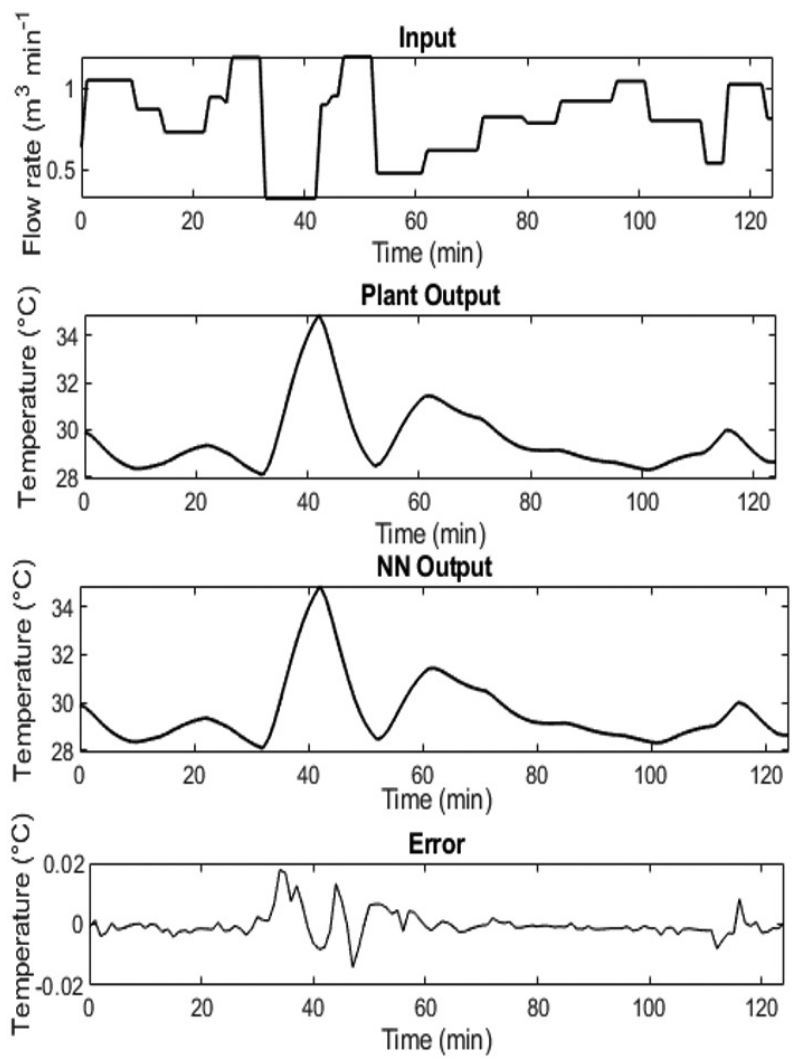

Fig. 5. Validation data for NN model. 
process inputs, three delayed process outputs, and one hidden layer with six neurons and 1,500 training samples were used for training, validation, and testing. Training and validation results are shown in Figs. 4 and 5. A small prediction error confirms the success of the training.

The parameters' values in the performance criterion (4) used for the NNPC design were: horizons values: $N_{1}=1, N_{2}=7, N_{u}=2$, weight parameter: $\lambda=0.1$. The control input constraints were selected as follows: minimum control input: $q_{1 \text { min }}=0.01 \mathrm{~m}^{3} \mathrm{~min}^{-1}$, maximum control input: $q_{1 \max }=1 \mathrm{~m}^{3} \mathrm{~min}^{-1}$.

\section{Neural-network-predictive-control-based control systems}

\section{NNPC-based cascade control}

Cascade control, which represents a multi-loop control structure with an auxiliary controlled variable, is often used in the process industry to improve the quality of feedback control when certain types of disturbances and uncertainties occur (Bequette, 2003).

This setting shows one manipulated variable and more than one measured variables. The inner and outer control loops contain separate feedback controllers. The main advantage of using cascade control is that the disturbances occurring in the secondary loop are corrected by the secondary controller before they affect the primary controlled output value. The primary controller is usually tuned as a controller with integral action because it is responsible for the control objective achievement and steady-state error removal. The secondary controller has to compensate the load disturbance as fast as possible; usually, high gain $\mathrm{P}$ controller is used for very fast action. The secondary controller is tuned first and the primary controller is tuned with the inner loop in action. Because the behavior of the controlled process is often non-linear and asymmetric, and since the internal loop dynamics has to be taken into account, tuning the primary controller is not simple (Ogunnaike and Ray, 1994). Thus, the neural network model of the controlled process can be used to improve the tuning of the primary controller (Fig. 6). Primary controlled output was the temperature of the cooled fluid in the outlet stream of the $4^{\text {th }} \mathrm{HE}$. The primary NN predictive controller settings were as follows: four delayed process inputs, three delayed process outputs and one hidden layer with six neurons, and 1,000 training samples were used for training, validation, and testing. Parameters' values in the performance criterion (4) were: horizons: $N_{1}=1, N_{2}=7, N_{u}=4$, weight parameter: $\lambda=0.01$, minimum controlled output: $T_{\text {cmin }}=25{ }^{\circ} \mathrm{C}$, maximum controlled output: $T_{\text {cmax }}=180{ }^{\circ} \mathrm{C}$. The conventional $\mathrm{P}$ controller was used as a secondary controller to compensate load disturbance as quickly as possible. The secondary controlled output was the cold water flow rate in the inlet stream into the $4^{\text {th }} \mathrm{HE}$. The gain of the secondary $\mathrm{P}$ controller was $-0.04{ }^{\circ} \mathrm{C}^{-1} \mathrm{~min}^{-1} \mathrm{~m}^{3}$.

\section{NNPC-based control system with disturbance measurement}

Feedback control is usually used with feedforward control to combine the advantages and avoid the disadvantages of both control structures (Bequette, 2003). The feedforward controller, also called a compensator, compensates for the effect of disturbances on the controlled variable if both an accurate model of the controlled process and an accurate model of the disturbance process for measurable disturbance are used. The control loop with feedforward compensation of the disturbance is forced to eliminate the influence of the disturbance to its full extent. By introducing a compensator in the feedforward loop, the disturbances are partially eliminated before they enter the feedback loop, and thus the feedback controller does not have to generate large control actions as in case of a simple feedback control loop.

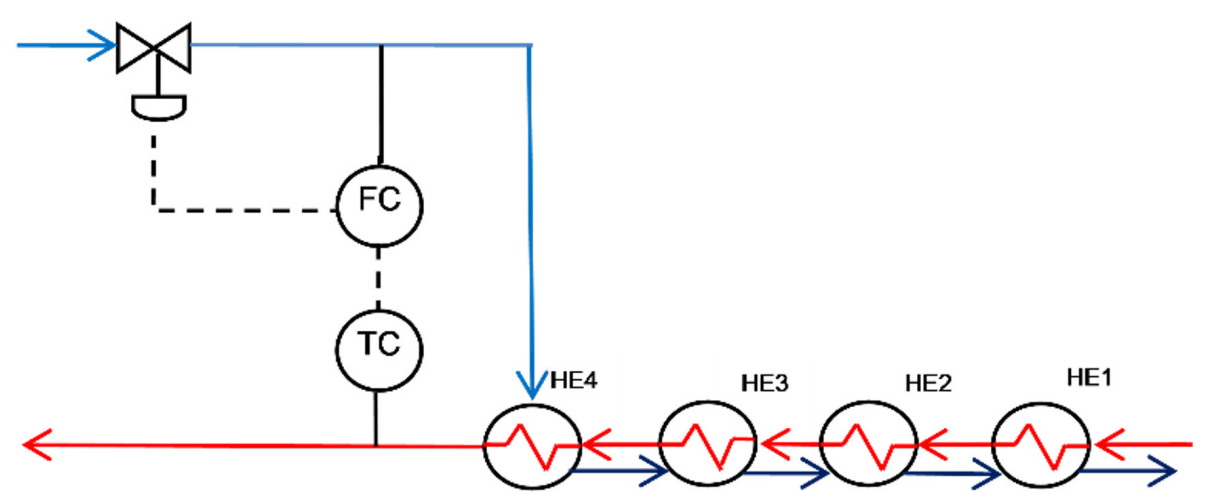

Fig. 6. NNPC-based cascade control for HEs, TC - primary NN predictive controller, $\mathrm{FC}-$ secondary conventional $\mathrm{P}$ controller. 


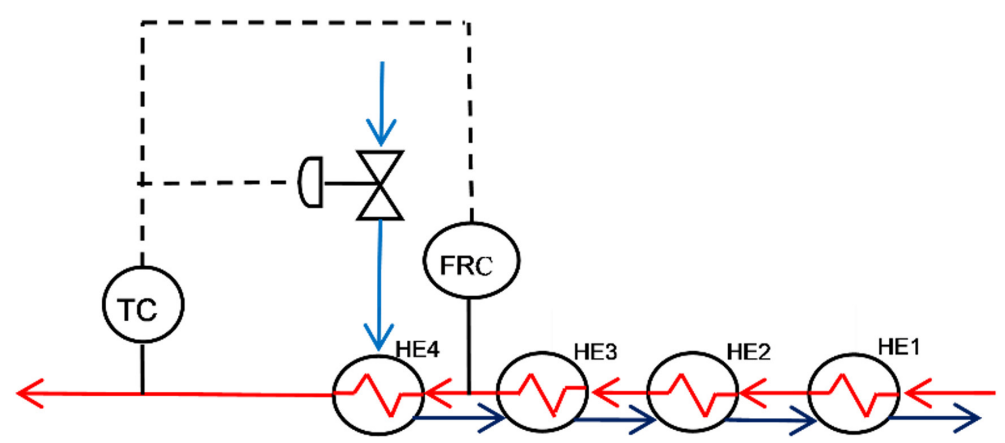

Fig. 7. NNPC-based control system with disturbance measurement for HEs, TC - NN predictive feedback controller, FRC - feedforward compensator.

In the designed NNPC-based control system with disturbance measurement (Fig. 7), feedforward control is used in combination with the NNPCbased feedback control. The NN predictive controller described in section Conventional neural network predictive control of HEs was used as the feedback controller. The transfer function of the feedforward compensator was calculated from the transfer functions of the controlled system and the disturbance process and it was simplified to the conventional $\mathrm{P}$ controller with the gain of $0.001{ }^{\circ} \mathrm{C}^{-1} \mathrm{~min}^{-1} \mathrm{~m}^{3}$.

\section{Simulation results}

Simulation results obtained using the designed control systems without and with measurement noise are presented in Figs. 8 and 9, respectively. The simulation results were compared according to the total cooling agent consumption, $V_{\text {total, }}$ consumed during control, and the integral IAE (integrated absolute error) and ISE (integrated squared error) quality criteria defined e.g. in Ogunnaike and Ray (1994) as follows:

$$
\begin{aligned}
& \mathrm{IAE}=\int_{0}^{\infty}|e(t)| \mathrm{d} t \\
& \mathrm{ISE}=\int_{0}^{\infty} e(t)^{2} \mathrm{~d} t
\end{aligned}
$$

Reference temperature $r=34{ }^{\circ} \mathrm{C}$ changed to $32^{\circ} \mathrm{C}$ at $60 \mathrm{~min}$ and then to $31^{\circ} \mathrm{C}$ at $120 \mathrm{~min}$.

The simulation results in reference tracking and disturbance rejection without measurement noise are presented in Fig. 8. Table 1 summarizes the obtained numerical results. Consumption of the cooling agent expressed by the total consumed volume, $V_{\text {total }}$, and the values of IAE and ISE was the lowest with the NNPC-based cascade control.

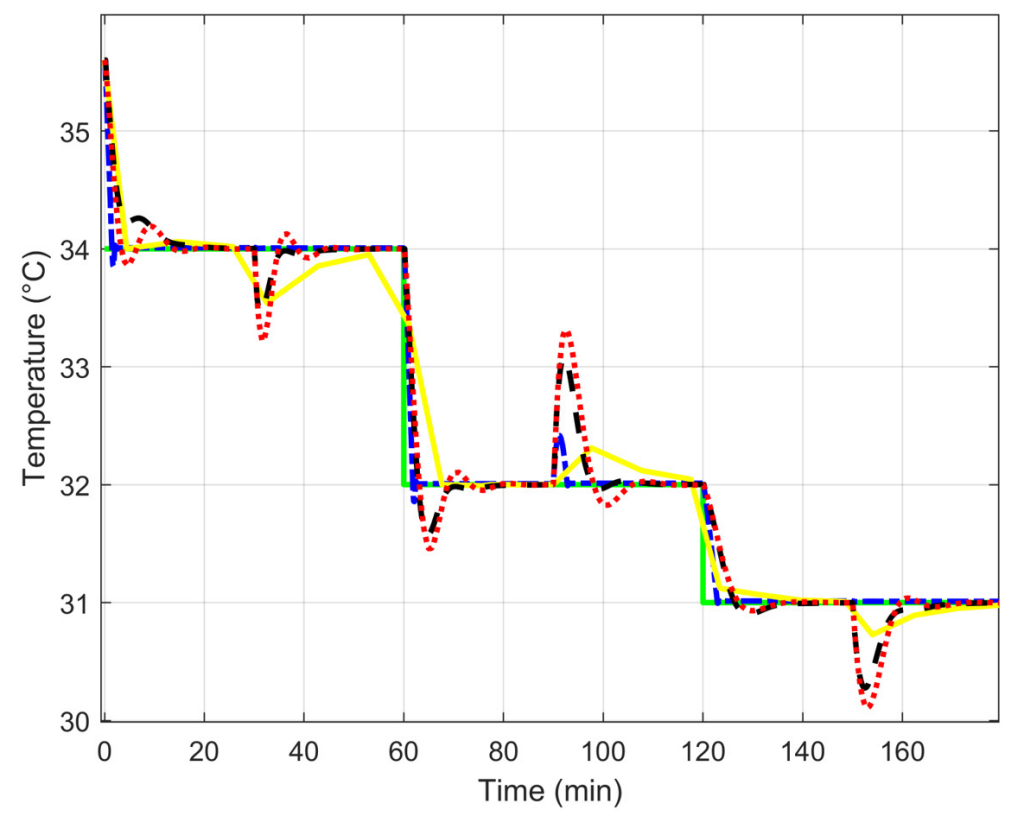

Fig. 8. Controlled temperature without measurement noise. 


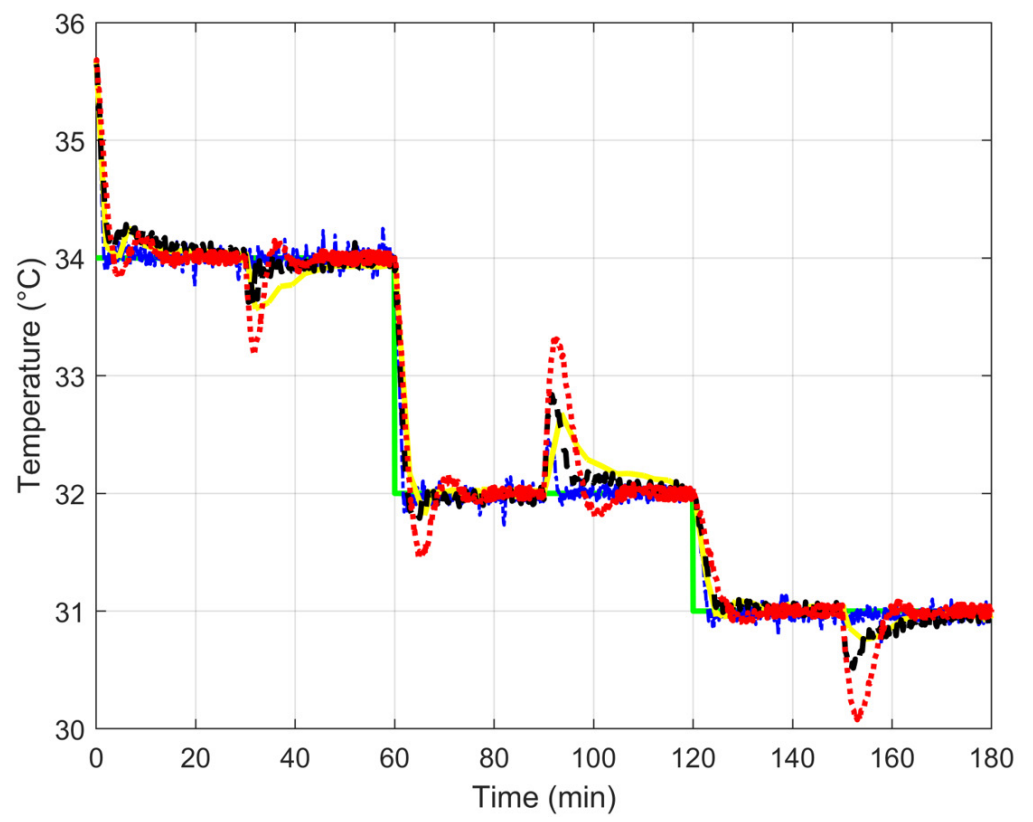

Fig. 9. Controlled temperature with measurement noise.

Tab. 1. Values of IAE, ISE, and $V_{\text {total }}$ in simulation experiments without measurement noise.

\begin{tabular}{lccc}
\hline Control system & IAE $\left({ }^{\circ} \mathbf{C}\right.$ min $)$ & ISE $\left({ }^{\circ} \mathbf{C}^{2} \mathbf{m i n}\right)$ & $\boldsymbol{V}_{\text {total }}\left(\mathbf{m}^{3}\right)$ \\
\hline PI control & 27.86 & 21.18 & 84.02 \\
NNPC & 24.73 & 17.16 & 83.94 \\
NNPC-based cascade control & 7.38 & 5.69 & 83.12 \\
NNPC-based control system with disturbance measurement & 22.27 & 12.02 & 84.26 \\
\hline
\end{tabular}

Tab. 2. Values of IAE, ISE, and $V_{\text {total }}$ in simulation experiments with measurement noise.

\begin{tabular}{lccc}
\hline Control system & IAE $\left({ }^{\circ} \mathbf{C}\right.$ min $)$ & ISE $\left({ }^{\circ} \mathbf{C}^{2} \mathbf{m i n}\right)$ & $\boldsymbol{V}_{\text {total }}\left(\mathbf{m}^{3}\right)$ \\
\hline PI control & 28.13 & 21.69 & 84.56 \\
NNPC & 23.80 & 11.83 & 84.30 \\
NNPC-based cascade control & 12.36 & 5.81 & 83.62 \\
NNPC-based control system with disturbance measurement & 22.47 & 12.45 & 84.95 \\
\hline
\end{tabular}

In Figs. 8 and 9, the reference is represented by the green solid line and the controlled output is indicated as follows: red dotted line - PI control, black dashed line - NNPC, blue dashed-dotted line - NNPC-based cascade control, yellow line NNPC-based control system with disturbance measurement.

The simulation results in reference tracking and disturbance rejection with measurement noise are presented in Fig. 9. Table 2 summarizes the obtained numerical results. Consumption of cooling agent, $V_{\text {total }}$, and the values of IAE and ISE were the lowest when using the NNPC-based cascade control.

\section{Conclusions}

Conventional PI controller designed using the Chien-Hrones-Reswick method and NNPC were compared to a complex two-controller control structure, namely NNPG-based cascade control, and NNPG-based control system with disturbance measurement. These advanced control strategies were used to control four heat exchangers in series with counter current configuration. Simulation results in reference tracking and disturbance rejection without noise and with measurement noise were compared. According to the IAE and ISE criteria, all control structures with NNPC have overcome conventional PI control. Results of the simulation experiments showed that the NNPC-based cascade control reduced both, the settling time and overshoots. The best results were achieved when using the NNPC-based cascade control, as confirmed by the IAE and ISE criteria, as well as to the minimum volume of consumed cooling water. Cascade control is often used to eliminate unmeasurable 
disturbances and accelerate process response. From this perspective, the NNPC-based cascade control strategy is suitable to be implemented in practice with promising control performance.

\section{Acknowledgment}

The authors gratefully acknowledge the contribution of the Scientific Grant Agency of the Slovak Republic under the grant 1/0545/20.

\section{References}

Bakošová M, Oravec J, Vasičkaninová A, Mészáros A (2017) Neural-network-based and robust modelbased predictive control of a tubular heat exchanger. Chemical Engineering Transactions. 61: 301-306.

Baruque B, Porras S, Jove E, Calvo-Rolle JL (2019) Geothermal heat exchanger energy prediction based on time series and monitoring sensors optimization. Energy. 171: 49-60.

Beale MH, Hagan MT, Demuth HB (2015) Neural Network Toolbox ${ }^{\mathrm{TM}}$, User's Guide, MATLAB ${ }^{\circledR}$ R2015a, The MathWorks, Inc., Natick, MA, USA, 410 ps. ISBN: 0-9717321-0-8.

Bequette WB (2003) Process Control: Modeling, Design, and Simulation, Prentice-Hall of India, New Delhi, India, 800 ps. ISBN-10: 0133536408, ISBN-13: 978-0133536409.

Corriou JP (2004) Process Control - Theory and Applications, Springer, London, UK, 860 ps. Print ISBN 978-3-319-61142-6, Online ISBN 978-3-319-61143-3.

Lera G, Pinzolas M (2002) Neighborhood based Levenberg Marquardt algorithm for neural network training, IEEE Trans. Neural Networks 13(5): 1200-1203.

Elsisi M (2019) New design of adaptive model predictive control for energy conversion system with wind torque effect. Journal of Cleaner Production 240: 118265.

Kim J, Kim J, Kim J, Yoo CK, Moon I (2009) A simultaneous optimization approach for the design of wastewater and heat exchange networks based on cost estimation. Journal of Cleaner Production 17(2): 162-171.

Markowski M, Trzcinski P (2019) On-line control of the heat exchanger network under fouling constraints. Energy 185: 521-526.

Mikleš J, Fikar M (2007) Process Modeling, Identification, and Control, Springer, Berlin/Heidelberg, Germany. 480 ps. ISBN: 978-3-540-71969-4.

Nemet A, Klemeš JJ, Kravanja Z (2017) Heat exchanger network synthesis considering risk assessment for entire network lifetime. Chemical Engineering Transactions 57: 307-312.

Ogunnaike BA, Ray WH (1994) Process Dynamics, Modelling, and Control, Oxford University Press, New York, USA, 1260 ps. ISBN: 978-0195091199.

Oravec J, Bakošová M, Meszáros A (2016) Robust model predictive control of heat exchangers in series, Chemical Engineering Transactions 52: 253-258.

Oravec J, Bakošová M, Trafczynski M, Vasičkaninová A, Mészáros A, Markowski M (2018) Robust model predictive control and PID control of shell-and-tube heat exchangers. Energy 159: 1-10.

Pashchenko D (2020) A heat recovery rate of the thermochemical waste-heat recuperation systems based on experimental prediction. Energy. 198: 117395.

Saranya SN, Thirumarumurugan M, Sivakumar VM, Sowparnika GC (2017) An Optimal Analysis of Controller Strategies for Different Heat Exchangers A Review. Middle-East Journal of Scientific Research. 25(4): 761-775. ISSN 1990-9233.

Soloway D, Haley PJ (1996) Neural generalized predictive control, Proceedings of the 1996 IEEE International Symposium on Intelligent Control, Dearborn, MI, USA, 277-281.

Sun F, Chen X, Fu L, Zhang S (2018) Configuration optimization of an enhanced ejector heat exchanger based on an ejector refrigerator and a plate heat exchanger. Energy 164: 408-417.

Vasičkaninová A, Bakošová M (2015) Control of a heat exchanger using neural network predictive controller combined with an auxiliary fuzzy controller, Applied Thermal Engineering 89: 1046-1053.

Vasičkaninová A, Bakošová M, Oravec J, Mészáros A (2017) Neural network predictive controller design for counter-current tubular heat exchangers in series, Chemical Engineering Transactions 61: 121-126.

Vasičkaninová A, Bakošová M, Oravec J, Mészáros A (2019) Control of Heat Exchangers Using Complex Control Structures with Neural Network Predictive Controllers, Chemical Engineering Transactions 76: 361-366.

Yang A, Jin S, Shen W, Cui P, Chien, IL, Ren J (2019) Investigation of energy-saving azeotropic dividing wall column to achieve cleaner production via heat exchanger network and heat pump technique. Journal of Cleaner Production. 234: 410-422.

Yang F, Liu Y, Liu G (2016) A process simulation based benchmarking approach for evaluating energy consumption of a chemical process system, Journal of Cleaner Production. 112(4): 2730-2743. 